Bond University

Research Repository

\title{
Fluid, Energy and Nutrient Recovery via Ad Libitum Intake of Different Commercial Beverages and Food in Female Athletes
}

McCartney, Danielle; Irwin, Christopher; Cox, Gregory R; Desbrow, Ben

Published in:

Canadian Journal of Applied Physiology

DOI:

10.1139/apnm-2018-0176

Licence:

CC BY-NC-ND

Link to output in Bond University research repository.

Recommended citation(APA):

McCartney, D., Irwin, C., Cox, G. R., \& Desbrow, B. (2019). Fluid, Energy and Nutrient Recovery via Ad Libitum Intake of Different Commercial Beverages and Food in Female Athletes. Canadian Journal of Applied Physiology, 44(1), 37-46. https://doi.org/10.1139/apnm-2018-0176

\section{General rights}

Copyright and moral rights for the publications made accessible in the public portal are retained by the authors and/or other copyright owners and it is a condition of accessing publications that users recognise and abide by the legal requirements associated with these rights.

For more information, or if you believe that this document breaches copyright, please contact the Bond University research repository coordinator. 


\section{Fluid, Energy and Nutrient Recovery via Ad Libitum Intake of Different 2 Commercial Beverages and Food in Female Athletes}

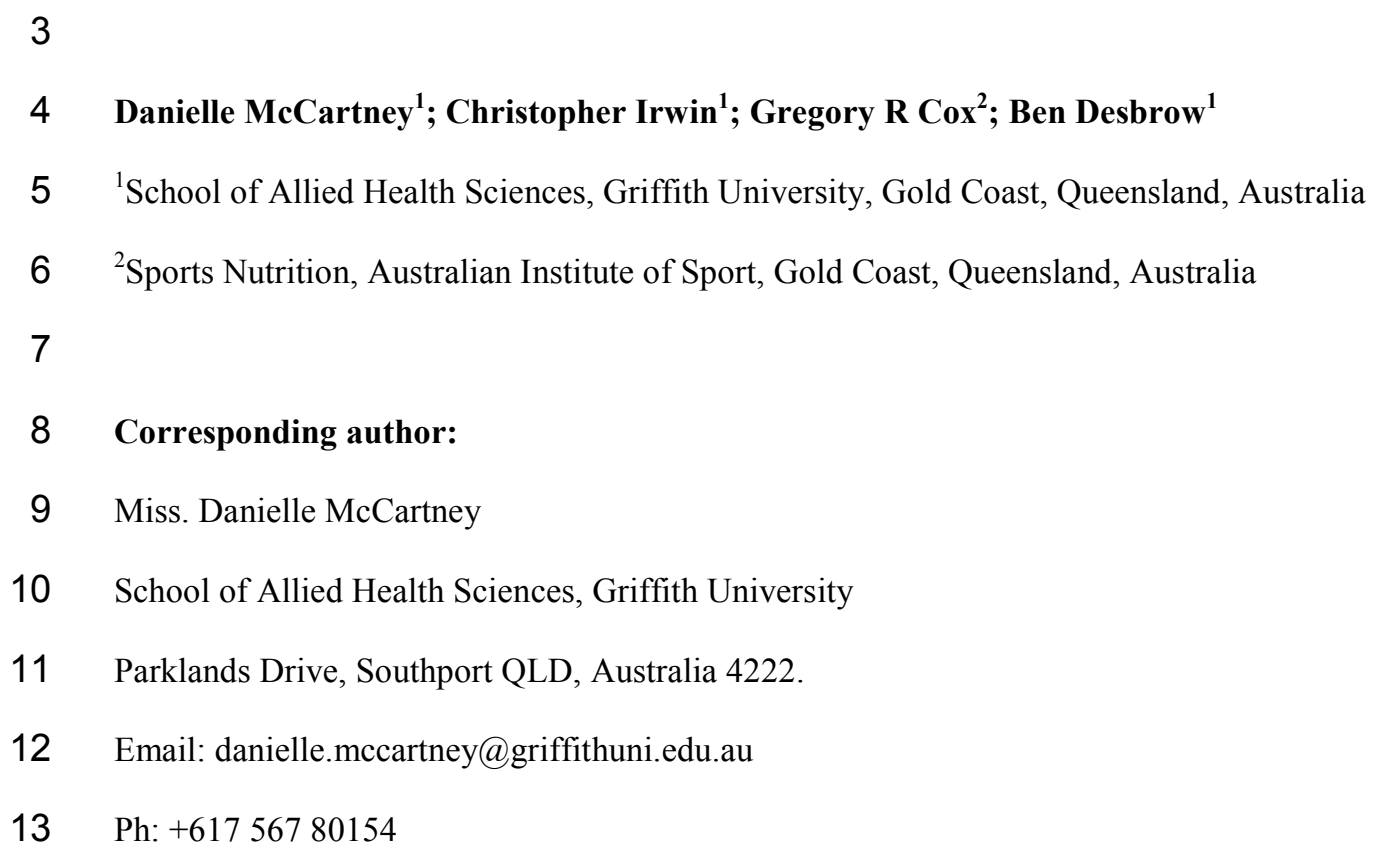




\section{Abstract:}

15 Purpose: This study investigated the effect of consuming different commercial beverages with food ad libitum post16 exercise on fluid, energy and nutrient recovery in trained females. Methods: On 4 separate occasions, 8 females 17 (body mass $[\mathrm{BM}]: 61.8 \pm 10.7 \mathrm{~kg} ; \mathrm{VO}_{2 \max }: 46.3 \pm 7.5 \mathrm{~mL} \cdot \mathrm{kg}^{-1} \cdot \mathrm{min}^{-1}$ ) lost $2.0 \pm 0.3 \% \mathrm{BM}$ cycling at $\sim 75 \% \mathrm{VO}_{2 \max }$ before 18 completing a 4 h recovery period with ad libitum access to one of 4 beverages: Water, Powerade ${ }^{\circledR}$ (Sports Drink), 19 Up \& Go Reduced Sugar ${ }^{\mathrm{TM}}$ (Lower Sugar [LS]-MILK) or Up \& Go Energize ${ }^{\mathrm{TM}}$ (Higher Protein [HP]-MILK). 20 Participants also had $2 \times 15 \mathrm{~min}$ opportunities to access food within the first $2 \mathrm{~h}$ of the recovery period. Beverage 21 intake; total water/nutrient intake; and indicators of fluid recovery (BM, urine output, plasma osmolality $\left.\left[\mathrm{P}_{\mathrm{OSM}}\right]\right)$, 22 gastrointestinal (GI) tolerance and palatability were assessed periodically. Results: While total water intake (from 23 food and beverage) (Water: 1918 $\pm 580 \mathrm{~g}$; Sports Drink: 1809 $\pm 338 \mathrm{~g}$; LS-MILK: $1458 \pm 431 \mathrm{~g}$; HP-MILK: 1523 $\pm 472 \mathrm{~g}$; $24 p=0.010$ ) and total urine output (Water: 566 $\pm 314 \mathrm{~g}$; Sports Drink: 459 $\pm 290 \mathrm{~g}$; LS-MILK: 220 $\pm 53 \mathrm{~g}$; HP-MILK: $25230 \pm 117 \mathrm{~g} ; p=0.009)$ differed significantly by beverage, the quantity of ingested water retained was similar across 26 treatments (Water: 1352 $\pm 462 \mathrm{~g} ;$ Sports Drink: 1349 $\pm 407 \mathrm{~g} ; \quad$ LS-MILK: 1238 $\pm 400 \mathrm{~g}$; HP-MILK: 1293 $\pm 453 \mathrm{~g}$; $27 p=0.691$ ). Total energy intake (from food and beverage) increased in proportion to the energy density of the

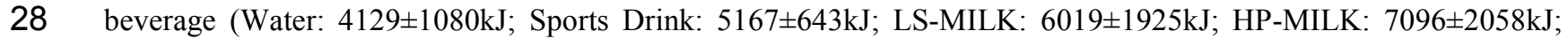
$29 p=0.014)$. Conclusion: When consumed voluntarily and with food, different beverages promote similar levels of 30 fluid recovery, but alter energy/nutrient intakes. Providing access to food and understanding the longer-term dietary 31 goals of female athletes are important considerations when recommending a recovery beverage.

33 Key words: Exercise Nutrition; Exercise Recovery; Hydration; Female Athlete; Eating Behavior 


\section{$34 \quad 1.0$. Introduction}

Athletes regularly complete competitive events and training sessions that result in substantial sweat loss (O'Neal et al. 2012). Typically, the quantity of fluid consumed during exercise is inadequate to replace these losses

37 (Garth and Burke 2013). Hence, individuals often finish activity in a state of body water deficit (dehydration).

38 Exercise may also be accompanied by the depletion of endogenous substrate stores and damage to skeletal muscle tissue (Moore 2015). Nutritional strategies that maximize recovery ahead of a subsequent exercise session are, therefore, important. Given the frequency with which athletes train, acute recovery strategies also have the potential to influence chronic nutrient/exercise interactions (e.g. metabolic adaptation and body composition changes). Hence, nutritional recovery recommendations should align with an athlete's broader dietary goals.

Nutrient recommendations designed to optimize recovery after exercise have been published by the American

44 College of Sports Medicine and the Academy of Nutrition and Dietetics (Sawka et al. 2007; Thomas et al. 2016).

45 These recommendations encourage individuals to ingest fluid (i.e. 1.25-1.50 L $\cdot \mathrm{kg} \mathrm{BM} \operatorname{los}^{-1}$ ) to restore euhydration 46 and consume carbohydrate (CHO) and protein to promote glycogen and muscle protein synthesis. Recent meta47 analyses also highlight the importance of fluid and CHO intake between consecutive exercise sessions to enhance 48 performance on the subsequent task (McCartney et al. 2017; McCartney et al. 2018). Given their ability to deliver 49 both fluid and nutrients, beverages have received considerable scientific attention in regard to their influence on 50 recovery. predetermined rate. Findings generally indicate that beverages with complex nutritional profiles (i.e. milk/milk-

54 based formulations) are more effective rehydration agents than beverages with basic nutritional profiles (i.e. water 55 and sports beverages) (Shirreffs et al. 2007b; Watson et al. 2008; Desbrow et al. 2014; Seery and Jakeman 2016). In 56 addition to fluid, these beverages also typically provide additional $\mathrm{CHO}$ and protein, making them ideal candidates 57 to aid post-exercise recovery. However, other factors such as thirst, palatability and gastrointestinal (GI) tolerance, 58 which are likely to influence the volume of fluid consumed in practice, are overlooked in studies where fluid intake 59 is prescribed. A small body of research investigating ad libitum fluid consumption behavior suggests that individuals 60 may consume different fluids in different quantities post-exercise (Nose et al. 1988; Wemple et al. 1997; Evans et al. 61 2009a; Park et al. 2012; Baguley et al. 2016), influencing their effectiveness as a recovery option. In addition to 
62 "prescribing" drinking, many studies also deny participants access to food: an approach with limited ecological 63 validity. Findings from studies that have allowed participants to eat as part of the experimental protocol generally

64 suggest that co-ingesting food and fluid improves rehydration, such that the magnitude of difference between 65 beverages with different nutrient profiles (i.e. in terms of their potential to rehydrate) is attenuated (Maughan et al. 66 1996; Brouns et al. 1998; Ray et al. 1998; Jones et al. 2010; Pryor et al. 2015; Campagnolo et al. 2017; Evans et al. 67 2017). Still, most studies have prescribed a small number of food items that may not reflect the participants' usual 68 dietary behavior.

To date, one only study (Campagnolo et al. 2017) has investigated the ability of different beverages to 70 rehydrate participants when the drink and a variety of foods are consumed ad libitum post-exercise. The study, 71 which involved 10 endurance-trained males, demonstrated that fluid recovery was similar, regardless of the type of 72 beverage consumed. This suggests that, with the co-ingestion of food, fluid restoration following exercise may not 73 be influenced by beverage choice. The type of beverage did, however, affect nutrient intake during the post-exercise 74 period. Specifically, the provision of a sports beverage or a milk-based formulation increased total (i.e. food and 75 beverage) energy ( $2500 \mathrm{~kJ})$ and $\mathrm{CHO}(\sim 200 \mathrm{~g})$ intake compared to water; the milk-based formulation also 76 increased total protein consumption ( $\sim 70 \mathrm{~g})$ compared to the other beverages. Hence, the choice of post-exercise 77 beverage may affect aspects of recovery and the suitability of certain beverages for athletes with specific dietary 78 goals. Different energy and nutrient requirements, dietary preferences and motives influencing food choice have the 79 potential to limit the generalizability of previous results. Indeed, it is currently unclear if these effects persist in 80 trained females, who may exhibit contrasting dietary behaviors (Leblanc et al. 2015). Furthermore, it remains 81 unclear how beverages with similar sensory characteristics (i.e. taste, aroma, appearance) but with contrasting 82 nutrient profiles affect fluid, energy and nutrient recovery following acute exercise, when consumed ad libitum and 83 when access to food is provided.

This study aimed to investigate the effect of consuming different commercial beverages (including milk86 based beverages with contrasting formulations) with food ad libitum post-exercise on fluid, energy and nutrient 87 recovery in active female subjects. We hypothesized that, when consumed voluntarily and with food, these beverages would result in similar levels of fluid recovery, but different energy/nutrient intakes. 


\subsection{Materials and Methods}

\section{$91 \quad 2.1$ Participant Characteristics}

Female cyclists/triathletes $\left(\geq 3 \mathrm{~h}\right.$ cycling $\left.\cdot \mathrm{week}^{-1}\right)$ aged $18-45$ y were eligible to participate in this investigation. Sample size was determined using power calculation software (G*Power Version 3.1.9.2, University

94 Kiel Germany, 2014). A comparable study of male cyclists (Campagnolo et al. 2017) detected a significant effect of 95 rehydration beverage (Water vs. Sustagen Sport ${ }^{\circledR}$ vs. Powerade $\left.{ }^{\circledR}\right)$ on energy intake $\left(\eta_{\mathrm{p}}{ }^{2}=0.62\right)$. Using a power $(1-\beta)$ of 0.95 and $\alpha=0.05$ with an equivalent effect, we predicted that 8 subjects would be required to detect a significant change. Ten participants were recruited to account for attrition. One participant withdrew after the familiarization because trials conflicted with her training schedule; a second individual withdrew after the first experimental trial due to poor availability. The 8 remaining participants (age: $33.2 \pm 7.4 \mathrm{y} ; \mathrm{VO}_{2 \max }: 46.3 \pm 7.5 \mathrm{~mL} \cdot \mathrm{kg}^{-1} \cdot \mathrm{min}^{-1}$; PPO: $244 \pm 32 \mathrm{~W}$; cycling: $115 \pm 60 \mathrm{~km} \cdot \mathrm{week}^{-1}$; Mean $\pm \mathrm{SD}$ ) completed all 4 experimental trials. This investigation was approved by the University's Human Ethics Committee (GU 2017/730) and procedures were conducted in accordance with principles outlined in the agreement of Helsinki.

\subsection{Study Design}

The experimental procedures are summarized in Figure 1. Each participant attended the laboratory on 6 separate occasions to complete one preliminary screening visit, one familiarization, and 4 repeated-measures experimental trials ( $\geq 5 \mathrm{~d}$ apart). Trials were counterbalanced for order using an incomplete Latin square design and scheduled during the first 14 days of the menstrual cycle (follicular phase) to minimize the confounding influence of hormonal changes on appetite and substrate utilization (Dye and Blundell 1997; Zderic et al. 2001). Participants using hormonal contraceptives at the time of the investigation $(n=3)$ completed testing whilst administering the active medication. Each experimental trial involved exercise-induced dehydration followed by a $4 \mathrm{~h}$ recovery period, with ad libitum access to one of 4 commercial beverages: (1) Water, (2) Powerade ${ }^{\circledR}$ Isotonic (Coca Cola Ltd.) 113 (Sports Drink), (3) Up \& Go Reduced Sugar ${ }^{\mathrm{s}}$ (Sanitarium ${ }^{\circledR}$, Australia) (Reduced Sugar [RS]-MILK), and (4) Up \& 114 Go Energize $^{\mathrm{TM}}$ (Sanitarium $^{\circledR}$, Australia) (Higher Protein [HP]-MILK). Drinking was permitted throughout the $4 \mathrm{~h}$ 115 recovery period. Participants also had $15 \mathrm{~min}$ to access food at the end of the $1^{\text {st }}$ and $2^{\text {nd }}$ hour. Individuals were 116 unaware that their food intake was being monitored. They were instead told that the purpose of the study was to 117 investigate the influence of different beverages on recovery of cognitive function (sham questions and cognitive 
118 function tasks were administered throughout the trials to maintain this deception). Each participant was fully 119 informed of the purpose of the study (and given the opportunity to withdraw their data) once data collection 120 activities for the entire study were complete.

\subsection{Eligibility and Participant Screening}

On arrival at the initial visit, individuals completed a medical questionnaire and the Eating Attitudes Test-26 124 (Garner 1982) (Part C only, to deemphasize the importance of dietary behavior to this study). Those with a history 125 of cardiovascular, metabolic and/or kidney disease, or currently taking medications known to influence substrate 126 metabolism were ineligible to participate. Individuals were also excluded if their responses indicated probable 127 disordered eating, as were volunteers who reported an allergy, intolerance or dislike towards the food items or test 128 beverages used in the investigation. Next, a self-reported body mass (BM) history $(\sim 6 \mathrm{~m})$ was collected and 129 anthropometric measurements were obtained using digital scales (HW-PW200; A\&D Company Ltd, Tokyo, Japan) 130 and a stadiometer. Participants had to be weight stable (BM change $\leq 5 \%$ in $1 \mathrm{~m}$ or $\leq 10 \%$ in $6 \mathrm{~m}$ ) and not followed 131 an energy-restricted diet during the previous $6 \mathrm{~m}$. Once eligibility was verified, participant's drink flavor preferences 132 where recorded and they were trained by a qualified dietitian on how to keep a $24 \mathrm{~h}$ diet record. Finally, participants 133 completed a graded exercise test on an electronically braked cycle ergometer (Lode Excalibur Sport; Lode BV, 134 Groningen, Netherlands) for determination of $\mathrm{VO}_{2 \max }$. The exercise protocol began at $50 \mathrm{~W}$, and increased in $30 \mathrm{~W}$ 135 increments every 2.5 min until volitional exhaustion. Participants' respiratory gases were sampled continuously by 136 breathing into a calibrated gas analysis system (Medgraphic Ultima, MGC Diagnostics and Medisoft, USA). Peak 137 sustainable power output (PPO) was also calculated (Jeukendrup et al. 1997) and used to establish the exercise intensity on subsequent trials.

\subsection{Familiarization}

Participants completed a full familiarization trial which employed a chocolate-flavored milk beverage

142 (different from those used in the experimental trials) as the recovery fluid. This allowed individuals to become 143 accustomed to the research protocol and the effects of consuming milk-products post-exercise.

\section{$145 \quad 2.5$ Pre-Trial Procedures}


Prior to each trial, participants were instructed to: (1) abstain from alcohol for $24 \mathrm{~h}$; (2) avoid caffeine147 containing products and moderate-strenuous exercise for $12 \mathrm{~h}$; (3) keep a written record of the food/fluid consumed 148 for $24 \mathrm{~h}$; (4) consume a standardized pre-packaged evening meal ( 60 kJ $\left.\mathrm{kg}^{-1}\right)$ (Campagnolo et al. 2017); and, (5) 149 fast from all food/fluid (including water) for $\sim 10 \mathrm{~h}$ (overnight). Food records were submitted to an investigator and 150 analyzed (FoodWorks ${ }^{\circledR}$ Version 8, Xyris Software Pty Ltd, Spring Hill, Australia) by one dietitian using the relevant 151 national food database. Following the initial trial, a copy of the food record was returned to the participant to assist 152 in the replication of the pre-trial dietary intake.

\section{$154 \quad 2.6$ Experimental Procedures}

\section{$155 \quad$ 2.6.1 Pre-Exercise Period}

Participants verbally acknowledged compliance to the pre-trial procedures and self-reported the onset of 157 menstruation on arrival at the laboratory ( 7 AM). A urine sample was collected to monitor hydration status (Urine 158 Specific Gravity $\left(\mathrm{U}_{\mathrm{SG}}\right)$ (Palette Digital Refractometer, ATAGO, USA). One participant had a pre-exercise $\mathrm{U}_{\mathrm{SG}}$ $159 \geq 1.024$ on the familiarization trial, indicating some level of dehydration (Armstrong et al. 2010). This individual was 160 administered water $(600 \mathrm{~mL})$ and, when reassessed 30 min later, $\mathrm{U}_{\mathrm{SG}}$ was $<1.024$. This practice was repeated on all 161 subsequent trials to ensure consistency. All remaining subjects produced initial $\mathrm{U}_{\mathrm{SG}}$ samples $<1.024$ at each 162 attendance. Euhydrated participants rested in the supine position for $15 \mathrm{~min}$ prior to respiratory gases $\left(\mathrm{VO}_{2}\right.$ and $\left.163 \mathrm{VCO}_{2}\right)($ Medgraphic Ultima, MGC Diagnostic Corporation, USA) being measured continuously for 10 min to 164 determine baseline metabolic rate. Following the respiratory measures, participants provided a blood sample, and 165 completed the cognitive function test and subjective feelings questionnaire (Adaptive Visual Analogue Scale 166 (AVAS); Marsh-Richard et al. (2009)). Individuals then voided their bladder completely and a pre-exercise nude 167 BM measurement was obtained.

\subsubsection{Dehydration and Exercise Protocol}

170 Dehydration was induced via passive heat exposure $\left(10 \mathrm{~min}, \sim 70^{\circ} \mathrm{C}\right.$, sauna $)$ followed immediately by 171 exercise on a cycle ergometer. Exercise commenced at a workload of $60 \%$ PPO $\left(24.2 \pm 0.9^{\circ} \mathrm{C} ; 66 \pm 11 \% \mathrm{RH}\right)$. 172 However, subjects who expressed likely volitional exhaustion prior to achieving the required BM loss (1.8\%) could 173 choose to reduce the workload by $5 \%$ PPO after 20 and 40 min of exercise (the minimum allowable workload was 
$17450 \%$ PPO). Heart rate (HR) and ratings of perceived exertion (RPE) on the Borg scale (Borg 1998) were collected at 17510 min intervals throughout exercise. Respiratory gases $\left(\mathrm{VO}_{2}\right.$ and $\left.\mathrm{VCO}_{2}\right)$ were measured continuously between $\sim 12-$ $17620 \mathrm{~min}, \sim 32-40 \mathrm{~min}$ and $\sim 52-60 \mathrm{~min}$ of exercise for determination of energy expended during exercise. Nude BM 177 was measured after 60 min of cycling. If BM loss was $<1.8 \%$ from baseline, participants were required to continue 178 exercise in $10 \mathrm{~min}$ intervals (respiratory gasses were collected across the final $5 \mathrm{~min}$ of each additional $10 \mathrm{~min}$ 179 block). Once a BM loss $\geq 1.8 \%$ was achieved, exercise ceased. The duration and intensity of the exercise was 180 documented during the familiarization and replicated on all subsequent trials. Participants repeated the cognitive 181 function test and responded to the subjective feelings questionnaire immediately after exercise. Individuals then 182 rested in a supine position and a blood sample was drawn. After resting $\sim 15$ min, respiratory gases were collected 183 continuously for a final 10 min. Individuals then showered and dried themselves before a final nude BM 184 measurement was obtained. The change in BM due to fluid loss was calculated by subtracting the final post-exercise 185 BM from the pre-exercise BM.

\subsubsection{Nutrition Recovery Period}

Participants completed a $4 \mathrm{~h}$ recovery period in an observation room adjacent to the exercise laboratory, where they were allowed to undertake sedentary activities. Participants were given immediate access to one of 4 commercial beverages (Water, Sports Drink [Energy: $103 \mathrm{~kJ} \cdot \mathrm{dL}^{-1}$; CHO: $5.8 \mathrm{~g} \cdot \mathrm{dL}^{-1}$; Sodium: $28 \mathrm{mg} \cdot \mathrm{L}^{1}$; Water: 95.0 $\mathrm{g} \cdot \mathrm{dL}^{-1}$ ], LS-MILK [Energy: $279 \mathrm{~kJ} \cdot \mathrm{dL}^{-1}$; CHO: $8.9 \mathrm{~g} \cdot \mathrm{dL}^{-1}$; Protein: $3.4 \mathrm{~g} \cdot \mathrm{dL}^{-1}$; Fat: $1.5 \mathrm{~g} \cdot \mathrm{dL}^{-1}$; Sodium: $65 \mathrm{mg} \cdot \mathrm{L}^{1}$; Water: $84.4 \mathrm{~g} \cdot \mathrm{dL}^{-1}$ ], or HP-MILK [Energy: $344 \mathrm{~kJ} \cdot \mathrm{dL}^{-1}$; CHO: $9.9 \mathrm{~g} \cdot \mathrm{dL}^{-1}$; Protein: $6.7 \mathrm{~g} \cdot \mathrm{dL}^{-1}$; Fat: $1.5 \mathrm{~g} \cdot \mathrm{dL}^{-1}$; Sodium: $100 \mathrm{mg} \cdot \mathrm{L}^{1}$; Water: $\left.\left.84.4 \mathrm{~g} \cdot \mathrm{dL}^{-1}\right]\right)$ in excess of expected consumption $(\sim 3.0 \mathrm{~L})$. They were told that the two milk-drinks were different, but no further product information was provided. (Participants were not permitted to change flavors between milk trials). All beverages were stored in refrigerators $\left(\sim 4^{\circ} \mathrm{C}\right)$ in opaque jugs. Participants were instructed to "self-serve" into cups and to "drink as much as they liked", as additional fluid would be provided upon request. The beverage vessels did not have volume increments. Palatability was evaluated at the onset of drinking and at the conclusion of the recovery period.

After $1 \mathrm{~h}$, participants completed the subjective feelings questionnaire, collected urine output, provided a blood sample, and measured nude BM. They were then given access to a variety of foods for $15 \mathrm{~min}$. Participants 
202 bring their beverage, but were asked to refrain from taking other external items. This approach was designed to 203 avoid social interactions which may influence eating behaviors and to reinforce the importance of the cognitive task.

204 Food items included sports bars, fresh fruit, breads and condiments (Supplementary Table S1) with participants 205 being instructed to "eat as much as they liked" and that "more of the same food would be provided in 1 h but no 206 food could be removed from the private room due to health and safety regulations". Participants were also informed 207 that no food would be provided in the $3^{\text {rd }}$ and $4^{\text {th }}$ hour of recovery. In the final 2 min, participants completed the 208 cognitive function test and then returned to the main observation room. These procedures (excluding blood 209 sampling) were repeated at the end of the $2^{\text {nd }}$ hour of the recovery period. At the end of the $3^{\text {rd }}$ and $4^{\text {th }}$ hour, 210 participants completed the cognitive function test and subjective feelings questionnaire, collected urine output and 211 measured nude BM. Blood sampling was also performed at the end of the $4^{\text {th }}$ hour.

\section{$213 \quad 2.7$ Post-Trial Procedures}

214 On leaving the laboratory, participants were required to keep a record of the food/fluid they consumed over 215 the remainder of the day, and to capture images of each item using a tablet device (iPad, Apple ${ }^{\circledR}$, Cupertino, USA). 216 Participants were encouraged to include a fiducial marker in each image, to assist the investigator in the estimation 217 of portion size. Food records and accompanying images were submitted to an investigator and checked for 218 completeness. Diet records were analyzed using the method previously described. A limit of up to two standard 219 alcoholic drinks (20 g alcohol) was imposed on trial days to avoid alcohol's influence on appetitive responses 220 (Poppitt 1996).

\subsection{Study Completion Procedures}

At the conclusion of the experiment, participants were asked what they believed the true purpose of the 224 investigation was, and, how confident they were that their answer was correct to verify that deception was effective. 225 Individuals also completed the R18 Three-Factor Eating Questionnaire (de Lauzon et al. 2004) to measure 226 influencers of eating behavior. 
Energy, macronutrient, sodium and water intake during the recovery period was determined by weighing the food (covertly) and beverages to the nearest $1 \mathrm{~g}$ after each hour. Participants were aware that beverage intake was

232 being monitored, but no information was provided to participants on how much fluid they consumed. Nutritional 233 values for packaged foods were taken from the product nutrition information panel; values for fresh food items and 234 product water content were derived from the dietary analysis software.

235

\subsubsection{Estimated Energy Expenditure}

Gas exchange data was averaged in $30 \mathrm{~s}$ segments over the final $\sim 8 \mathrm{~min}$ of each collection period. Estimated 238 energy expenditure (eEE) was then quantified in the following increments: pre-exercise (-20-0 min), exercise blocks 2391 (0-20 $\mathrm{min}), 2(20-40 \mathrm{~min})$ and $3(40-60 \mathrm{~min})$, post-exercise $(60-80 \mathrm{~min})$, and total trial (100 min). (Where 240 participants continued exercise in $10 \mathrm{~min}$ intervals after $60 \mathrm{~min}$, eEE was also quantified at exercise block 4 (60-70

$241 \mathrm{~min}$ ), such that the total trial time increased to $110 \mathrm{~min}$ ). Rates and total substrate oxidation were calculated using 242 the equations of Frayn (1983) (assuming negligible protein oxidation). Energy equivalents of $16.75 \mathrm{~kJ} \cdot \mathrm{g}^{-1}$ of $\mathrm{CHO}$ 243 and $37.68 \mathrm{~kJ} \cdot \mathrm{g}^{-1}$ of fat were utilized to calculate eEE from substrate oxidation (Schubert et al. 2014).

\subsubsection{Urine Sampling and Water Retention}

At the end of each hour of the recovery period, participants voided their bladder completely into an empty 247 container for measures of hourly urine output and hourly $\mathrm{U}_{\mathrm{SG}}$. Participants were permitted to urinate throughout the 248 observation period, and on each occasion, the void was collected and added to the hourly urine output. Total urine 249 loss was calculated as the accumulated urine output from the onset of drinking until the end of the observation 250 period. The proportion of ingested water retained at the end of the $4 \mathrm{~h}$ recovery period was calculated as total water 251 intake (i.e. food and beverage) minus total urine output and converted to a percentage of total water intake.

\subsubsection{Body Mass (BM) Measurements}

254 Nude BM measures were obtained pre- and $\sim 30$ min post-exercise (i.e. after sweating had ceased) and at the 255 end of each hour of the recovery period. All BM measurements were adjusted to account for the non-water mass of 256 the food and beverages consumed. 


\subsubsection{Subjective Feelings and Beverage Palatability Questionnaires}

Visual analogue scales (VAS) were used to measure subjective feelings of hunger, thirst and fullness pre- and post-exercise and at each hour of the recovery period. To distract participants from the primary outcomes of the study, individuals were also required to indicate feelings of alertness, concentration, muscle soreness and energy levels. VAS were also used to assess palatability ('pleasantness') at the onset of drinking and at the conclusion of the recovery period. Beverages were subsequently ranked from most to least palatable $\left(1^{\text {st }}-4^{\text {th }}\right)$ (based on individual participants' preferences) using the average pre/post-recovery palatability rating. All measures were conducted on a $100 \mathrm{~mm}$ scale, with $0 \mathrm{~mm}$ representing 'not at all' and $100 \mathrm{~mm}$ representing 'extremely' using a computerized modifiable software program (AVAS; Marsh-Richard et al. (2009)).

\subsubsection{Blood Sampling}

Participants rested for $\sim 5 \mathrm{~min}$ in a supine position prior to a $5 \mathrm{~mL}$ blood sample being drawn from an antecubital vein. Blood samples were obtained pre-exercise, post-exercise and at the end of the $1^{\text {st }}$ and $4^{\text {th }}$ hour of the recovery period. All samples were collected into pre-treated lithium heparin vacutainers (Becton Dickson vacutainers $\left.^{\circledR}\right)$ and centrifuged for $10 \min (\sim 1350 \times g)$. Aliquots of plasma supernatant were stored $\left(-80^{\circ} \mathrm{C}\right)$ and later analyzed in duplicate for plasma osmolality $\left(\mathrm{P}_{\mathrm{OSM}}\right)$ using a calibrated, freezing-point depression osmometer (Osmomat 030, Gonotec).

\subsection{Statistical Analysis}

Statistical analyses were completed using SPSS Statistics for Windows, Version 21.0 (IBM Corp. 2012, 278 Armonk, N.Y., USA). All measures were examined for normality (Shapiro-Wilk test) and sphericity (Mauchly's 279 test). Where assumptions of sphericity in repeated measures analyses were violated, the Greenhouse-Geisser statistic was applied. Comparisons between experimental trials for baseline measures (BM, $\mathrm{U}_{\mathrm{SG}}$, and $\left.\mathrm{P}_{\mathrm{OSM}}\right)$; exercise-induced 281 fluid loss; eEE; previous-day energy and water intake; beverage intake; water intake from beverage $\left(\mathrm{WI}_{\text {Beverage }}\right)$, food

$282\left(\mathrm{WI}_{\mathrm{Food}}\right)$ and beverage plus food $\left(\mathrm{WI}_{\mathrm{Total}}\right)$; energy intake from beverage $\left(\mathrm{EI}_{\text {Beverage }}\right)$, food $\left(\mathrm{EI}_{\mathrm{Food}}\right)$ and beverage plus 283 food $\left(\mathrm{EI}_{\text {Total }}\right)$; nutrient intake; urine output; and water retention were performed using one-way repeated measures 284 analysis of variance (ANOVA). The remaining variables were examined using a two-way (Treatment $\times$ Time) 
286 (Bonferroni). One-way ANOVA (Bonferroni) were used to conduct post hoc comparisons where significant 287 interaction effects were present. Each of the 18 items on the Three-Factor Eating Questionnaire was given a score 288 between 1 and 4 and item scores were summated into raw scores for cognitive restraint, uncontrolled eating, and 289 emotional eating. Raw scale scores were then transformed to a 0-100 scale [((raw score - lowest possible raw 290 score $/$ possible raw score range $) \times 100$ ]. Higher scores in the respective scales are indicative of greater cognitive 291 restraint, uncontrolled, or emotional eating (de Lauzon et al. 2004). Effect sizes are reported as partial eta squared $292\left(\eta_{\mathrm{p}}{ }^{2}\right)$. Significant differences were accepted as $p<0.05$. Data are Mean \pm SD, unless otherwise indicated.

\section{$294 \quad 3.0$ Results}

\section{$295 \quad 3.1$ Standardization Procedures}

296 All 8 participants verbally acknowledged compliance to the pre-experimental procedures on arrival at the 297 laboratory. Participants' pre-trial records indicated similar energy, $\mathrm{F}(3,21)=1.78, p=0.182$; and water, $298 \mathrm{~F}(3,21)=0.555, p=0.651$; intakes $24 \mathrm{~h}$ prior to each experimental trial (Water: $9.2 \pm 1.8 \mathrm{MJ}, 4.5 \pm 0.7 \mathrm{~L}$; Sports Drink:

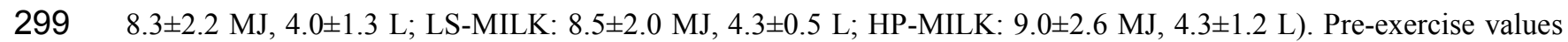
300 for $\mathrm{BM}, \mathrm{U}_{\mathrm{SG}}$ and $\mathrm{P}_{\mathrm{OSM}}$ were also similar across treatments (Table 1).

\subsection{Exercise-Induced Dehydration}

All participants successfully replicated the same exercise protocol at each experimental trial. For three 304 individuals, the total exercise duration was $70 \mathrm{~min}$; the remainder cycled $60 \mathrm{~min}$ to achieve the target BM loss. Gas 305 exchange data indicate that participants exercised at an intensity corresponding to $76 \pm 5 \% \mathrm{VO}_{2 \max }$. Neither $\mathrm{BM}$ loss 306 nor eEE differed significantly by treatment (Table 1) or by trial order, $\mathrm{F}(3,21)=0.279, p=0.840 ; \mathrm{F}(3,21)=0.806$, $307 p=0.504$, respectively. 4 (Treatment) $\times 6$ (Time) analyses of RPE and HR identified a significant main effect of time 308 on each variable, $\mathrm{F}(1.3,9.1)=16.79, p=0.002 ; \mathrm{F}(1.8,12.5)=16.0, p<0.001$, respectively. A significant main effect of 309 treatment was also observed on $\mathrm{HR}, \mathrm{F}(3,12)=3.21, p=0.044$; however, pairwise comparisons did not detect any 310 differences across trials ( $p$ 's $>0.05$ ). No main effect of treatment was observed on RPE, $\mathrm{F}(3,21)=2.07, p=0.134$.

\section{3.3 Water Intake from Food and Beverages}


314 in Supplementary Table S2. Beverage intake did not differ significantly by treatment (Table 2) or by trial order, $315 \mathrm{~F}(1.8,12.3)=0.569, p=0.558$. However, $\mathrm{WI}_{\text {Beverage }}$ was significantly lower with LS-MILK and HP-MILK compared to 316 Sports Drink $(p=0.040)$ and Water $(p=0.022)$, respectively. Whilst $\mathrm{WI}_{\text {Total }}$ also differed significantly across 317 treatments, pairwise comparisons only indicated a trend for a difference in $\mathrm{WI}_{\text {Total }}$ between HP-MILK and Water $318(p=0.080)$; no other differences were observed ( $p$ 's $>0.05)$. A 4 (Treatment $) \times 4$ (Time) analysis of mean hourly $319 \mathrm{WI}_{\text {Total }}$ identified a significant main effect of time, $\mathrm{F}(3,21)=62.4, p<0.001, \eta_{\mathrm{p}}{ }^{2}=0.90$; such that $\mathrm{WI}_{\text {Total }}$ was greater in 320 the $1^{\text {st }}$ hour of recovery $(864 \pm 195 \mathrm{~g})$ than all subsequent time points $\left(p^{\prime} s \leq 0.001\right)$; $\mathrm{WI}_{\text {Total }}$ did not differ across the $2^{\text {nd }}$ $321(315 \pm 42 \mathrm{~g}), 3^{\text {rd }}(307 \pm 119 \mathrm{~g})$ and $4^{\text {th }}(191 \pm 140 \mathrm{~g})$ hours of recovery $\left(p^{\prime} \mathrm{s}>0.05\right)$. No significant treatment $\times$ time 322 interaction was observed, $\mathrm{F}(9,63)=1.66, p=0.118, \eta_{\mathrm{p}}{ }^{2}=0.19$.

\subsection{Urine Output and Water Retention}

Total urine output differed significantly across treatments (Water: $556 \pm 314$ g; Sports Drink: $459 \pm 290$ g; LS-

326

327

328

329

330

331

332

333

334

335

336

337

338

339

340

MILK: $220 \pm 53 \mathrm{~g}$; HP-MILK: $\left.230 \pm 117 \mathrm{~g} ; \mathrm{F}(2.0,14.3)=6.57, p=0.009, \eta_{\mathrm{p}}{ }^{2}=0.48\right)$. Pairwise comparisons revealed that urine output was elevated with Water compared to HP-MILK $(p=0.048)$ and tended to be elevated compared to LS$\operatorname{MILK}(p=0.073)$; urine output was similar between all other treatments $(p$ 's $>0.05)$. A 4 (Treatment) $\times 4$ (Time) analysis of mean hourly urine outputs (Figure 2) indicated a main effect of time, $\mathrm{F}(3,21)=4.544, p=0.013, \eta_{\mathrm{p}}{ }^{2}=0.48$; such that mean urine output was greater during the $4^{\text {th }}$ hour of recovery than the $1^{\text {st }}$ hour $(p=0.027)$; but comparable across all other time points $(p$ 's $>0.05)$. No treatment $\times$ time interaction was observed, $\mathrm{F}(9,63)=1.25, p=0.281$, $\eta_{\mathrm{p}}{ }^{2}=0.15$. A 4 (Treatment) $\times 4$ (Time) analysis of mean hourly $\mathrm{U}_{\mathrm{SG}}$ (Figure 2$)$ values identified significant main effects of treatment, $\mathrm{F}(3,21)=17.7, p<0.001, \eta_{\mathrm{p}}{ }^{2}=0.72$; and time, $\mathrm{F}(3,21)=5.62, p=0.005, \eta_{\mathrm{p}}{ }^{2}=0.45$; and a significant treatment $\times$ time interaction, $\mathrm{F}(9,63)=5.70, p<0.001, \eta_{\mathrm{p}}{ }^{2}=0.45$. Post hoc comparisons revealed that Water decreased $\mathrm{U}_{\mathrm{SG}}$ compared to LS-MILK and HP-MILK between the $2^{\text {nd }}$ and $4^{\text {th }}$ hours of recovery $(p$ 's $<0.05)$; Sports Drink also decreased $\mathrm{U}_{\mathrm{SG}}$ compared to LS-MILK $(p=0.031)$ and HP-MILK $(p=0.032)$ during the $3^{\text {rd }}$ hour of recovery, and tended to decrease $\mathrm{U}_{\mathrm{SG}}$ compared to LS-MILK $(p=0.084)$ and HP-MILK $(p=0.054)$ during the $3^{\text {rd }}$ hour of recovery, although this was not at a level of statistical significance. The proportion (\%) of $\mathrm{WI}_{\text {Total }}$ retained differed

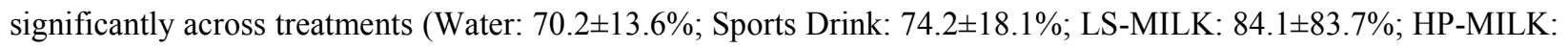
$\left.83.7 \pm 9.5 \% ; \mathrm{F}(3,21)=5.09, p=0.008, \eta_{\mathrm{p}}{ }^{2}=0.42\right)$. Pairwise comparisons revealed that water retention increased with 
341 LS-MILK compared to Water $(p=0.043)$, but similar across all other treatments $(p$ 's $>0.05)$. The overall quantity $(\mathrm{g})$ 342 of $\mathrm{WI}_{\text {Total }}$ retained at the conclusion of the experimental protocol did not differ significantly by treatment (Water: $3431352 \pm 462$ g; Sports Drink: $1349 \pm 407$ g; LS-MILK: $1238 \pm 400$ g; HP-MILK: $1293 \pm 453$ g; F(3,21)=0.493, $p=0.691$, $\left.344 \quad \eta_{\mathrm{p}}^{2}=0.0 .7\right)$

$346 \quad 3.5$ Body Mass Changes

Net BM changes are displayed in Figure 3. All trials concluded with participants in a state of negative net BM relative to pre-exercise values (Water: $-91 \pm 430 \mathrm{~g}$; SD: $-93 \pm 470 \mathrm{~g}$; LS-MILK: $-260 \pm 450 \mathrm{~g}$; HP-MILK: $-179 \pm 419$

349 g). A 4 (Treatment) $\times 6$ (Time) analysis of $\mathrm{BM}$ changes identified a significant main effect of time, $\mathrm{F}(1.4$, $35010.0)=51.0, p<0.001, \eta_{\mathrm{p}}{ }^{2}=0.88$; and a trend for a significant treatment $\times$ time interaction, $\mathrm{F}(15,105)=1.65, p=0.074$, $351 \eta_{\mathrm{p}}{ }^{2}=0.19$. However, post hoc comparisons failed to detect a difference between treatments at any time points $352(p ' s>0.05)$.

353

\subsection{Plasma Osmolality}

A 4 (Treatment) $\times 4$ (Time) analysis of $\mathrm{P}_{\mathrm{OSM}}$ values identified significant main effects of treatment, $356 \mathrm{~F}(3,18)=6.41, p=0.004, \eta_{\mathrm{p}}{ }^{2}=0.52$; and time, $\mathrm{F}(3,18)=46.7, p<0.001, \eta_{\mathrm{p}}{ }^{2}=0.89$; and a significant treatment $\times$ time 357 interaction, $\mathrm{F}(9,54)=15.5, p<0.001, \eta_{\mathrm{p}}{ }^{2}=0.72$. Pairwise comparisons indicated that $\mathrm{P}_{\mathrm{OSM}}$ increased following the 358 exercise-dehydration protocol ( $287 \pm 5$ vs. $\left.297 \pm 5 \mathrm{mOsm} \cdot \mathrm{kg}^{-1}, p<0.001\right)$. Post hoc comparisons suggested that Water 359 elicited lower $\mathrm{P}_{\mathrm{OSM}}$ values than LS-MILK $(p=0.001)$ and HP-MILK $(p=0.008)$ after the $1^{\text {st }}$ hour of recovery; Sports 360 Drink also reduced $\mathrm{P}_{\mathrm{OSM}}$ compared to LS-MILK $(p=0.012)$ at this time (Water: $287 \pm 5 \mathrm{mOsm} \cdot \mathrm{kg}^{-1}$; Sports Drink: $361291 \pm 8 \mathrm{mOsm} \cdot \mathrm{kg}^{-1}$; LS-MILK: $298 \pm 7 \mathrm{mOsm} \cdot \mathrm{kg}^{-1}$; HP-MILK: $\left.296 \pm 4 \mathrm{mOsm} \cdot \mathrm{kg}^{-1}\right)$. After the $4^{\text {th }}$ hour of recovery, 362 Water again elicited lower $\mathrm{P}_{\mathrm{OSM}}$ values than LS-MILK $(p=0.013)$ and HP-MILK $(p=0.004)$; Sports Drink also 363 reduced $\mathrm{P}_{\text {OSM }}$ compared to HP-MILK $(p=0.021)$ and tended to reduce $\mathrm{P}_{\mathrm{OSM}}$ compared in LS-MILK $(p=0.066)$ at this 364 time (Water: $288 \pm 5 \mathrm{mOsm} \cdot \mathrm{kg}^{-1}$; Sports Drink: $288 \pm 5 \mathrm{mOsm} \cdot \mathrm{kg}^{-1}$; LS-MILK: $295 \pm 5 \mathrm{mOsm} \cdot \mathrm{kg}^{-1}$; $\mathrm{HP}^{-M I L K}$ : $299 \pm 4$ $\left.365 \mathrm{mOsm} \cdot \mathrm{kg}^{-1}\right)$. 
Nutrient intakes during the $4 \mathrm{~h}$ recovery period and across the entire trial day (trial intake plus post-trial diet record) are displayed in Table 2; total energy consumed by individual participants is included in Supplementary 370 Table S2. Mean energy intake (food, beverage and total) differed significantly across treatments during the $4 \mathrm{~h}$ recovery period. Pairwise comparisons revealed that $\mathrm{EI}_{\mathrm{Food}}$ was significantly lower with HP-MILK compared to 372 Water $(p=0.005)$ and Sports Drink $(p=0.006)$; $\mathrm{EI}_{\mathrm{Food}}$ was also lower with LS-MILK compared to Water $(p=0.033)$ 373 and tended to suppress intake compared to Sports Drink ( $p=0.086)$. $\mathrm{EI}_{\text {Food }}$ did not differ significantly between Water 374 and Sports Drink $(p>0.05)$. Although not statistically significant, $\mathrm{EI}_{\text {Total }}$ tended to be increased with HP-MILK 375 compared to Water $(p=0.071)$ and Sports Drink $(p=0.085)$. Total CHO and protein intakes also differed significantly 376 across treatments during the $4 \mathrm{~h}$ recovery period. Pairwise comparisons revealed that Sports Drink $(p=0.004)$, LS377 MILK ( $p=0.026)$ and HP-MILK $(p=0.014)$ increased total CHO intake compared to Water; CHO intake was not different between the other beverages ( $p$ 's $>0.05$ ). LS-MILK and HP-MILK also increased total protein intake 379 compared to Water and Sports Drink $(p$ 's $<0.05)$; protein intake was also higher with HP-MILK compared to LSMILK ( $p=0.006$ ). Participants' post-trial intake of energy, water, CHO, fat and sodium did not differ significantly by treatment $(p$ 's $>0.05)$; only dietary protein intake was influenced by the beverage consumed post-exercise. Pairwise comparisons revealed a trend for decreased protein ingestion post-trial with HP-MILK compared to Sports Drink $(p=0.065)$. Nonetheless, $24 \mathrm{~h}$ protein intake with HP-MILK was higher than with all other beverages $(p$ 's $<0.05) .24$ $\mathrm{h}$ energy, $\mathrm{CHO}$ and sodium intakes differed significantly by treatment $\left(p^{\prime} \mathbf{s}<0.05\right)$. Although pairwise comparisons did not detect differences in total energy intake between trials ( $p$ 's $>0.05)$, LS-MILK and HP-MILK appeared to increase intake in comparison to Water and Sports Drink. Sports Drink $(p=0.076)$, LS-MILK $(p=0.022)$ and HPMILK ( $p=0.087)$ all tended to increase $24 \mathrm{~h} \mathrm{CHO} \mathrm{intake} \mathrm{compared} \mathrm{to} \mathrm{Water.}$

392 Post hoc comparisons revealed that LS-MILK and HP-MILK decreased subjective hunger compared to Water and 393 Sports Drink during the $1^{\text {st }}$ hour of recovery $(p$ 's $<0.05)$. Hunger ratings were not significantly different at any other 394 point in time $(p$ 's $>0.05) .4$ (Treatment) $\times 6$ (Time) analyses revealed significant main effects of treatment on thirst, $395 \mathrm{~F}(1.4,9.7)=34.4, p<0.001, \eta_{\mathrm{p}}{ }^{2}=0.83$; and fullness ratings, $\mathrm{F}(3,21)=3.81, p=0.025, \eta_{\mathrm{p}}{ }^{2}=0.35$; significant main effects 
396 of time on thirst, $\mathrm{F}(5,35)=22.1, p<0.001, \eta_{\mathrm{p}}{ }^{2}=0.76$; and fullness ratings, $\mathrm{F}(5,35)=27.9, p<0.001, \eta_{\mathrm{p}}{ }^{2}=0.80$; and 397 significant treatment $\times$ time interactions on thirst, $\mathrm{F}(15,105)=10.4, p<0.001, \eta_{\mathrm{p}}{ }^{2}=0.60$; and fullness ratings,

$398 \mathrm{~F}(15,105)=2.12, p=0.014, \eta_{\mathrm{p}}{ }^{2}=0.23$. Post hoc comparisons demonstrated that LS-MILK and HP-MILK increased 399 subjective fullness compared to Water during the $1^{\text {st }}$ hour of recovery $\left(p^{\prime} s<0.05\right)$. Fullness ratings were not 400 significantly different between treatments at any other point in time ( $p$ 's>0.05). Ingestion of LS-MILK and HP401 MILK increased thirst ratings compared to Water and Sports Drink at all stages of recovery $\left(p^{\prime} s<0.05\right)$.

\subsection{Beverage Palatability}

A 4 (Treatment) $\times 2$ (Time) analysis of beverage pleasantness ratings failed to indicate a significant main 405 effect of beverage, $\mathrm{F}(1.5,10.6)=1.97, p=0.150, \eta_{\mathrm{p}}{ }^{2}=0.22$; although, pleasantness ratings were generally increased 406 with Water $(79 \pm 30 \mathrm{~mm})$ and Sports Drink $(70 \pm 33 \mathrm{~mm})$ compared to LS-MILK $(50 \pm 16 \mathrm{~mm})$ and HP-MILK (56 $407 \pm 15 \mathrm{~mm})$. The analysis identified a significant main effect of time, $\mathrm{F}(3,7)=10.4, p=0.015, \eta_{\mathrm{p}}{ }^{2}=0.60$; such that 408 pleasantness decreased between the onset and conclusion of the drinking period (67 $\pm 9 \mathrm{~mm}$ vs. $60 \pm 10 \mathrm{~mm})$. Total 409 beverage intake also differed by palatability, $\mathrm{F}(3,21)=10.6, p<0.001, \eta_{\mathrm{p}}{ }^{2}=0.60$; such that the participants consumed a 410 significantly greater quantity of their most preferred beverage than their least- $(p=0.007)$ and second-least $(p=0.004)$ 411 preferred beverages $\left(1^{\text {st }}: 2057 \pm 498 \mathrm{~g} ; 2^{\text {nd }}: 1662 \pm 370 \mathrm{~g} ; 3^{\text {rd }}: 1471 \pm 389 \mathrm{~g} ; 4^{\text {th }}: 1515 \pm 496 \mathrm{~g}\right) .$. Average ratings for 412 the $1^{\text {st }}, 2^{\text {nd }}, 3^{\text {rd }}$ and $4^{\text {th }}$ most palatable beverages were $95 \pm 5 \mathrm{~mm}, 72 \pm 19 \mathrm{~mm}, 52 \pm 14 \mathrm{~mm}$ and $34 \pm 12 \mathrm{~mm}$, respectively.

\section{$414 \quad 3.10$ Post-Study Survey}

All 8 participants indicated that the purpose of the study was to investigate the effect of consuming different 416 beverages on recovery of cognitive function. Of these, 7 indicated they were either absolutely or very confident in 417 this response; one subject was somewhat confident. Mean \pm SD (Range) scores for Uncontrolled Eating, Cognitive 418 Restraint and Emotional Eating on the R18 Three-Factor Eating Questionnaire were: $33 \pm 11 \%$ (19-53\%), $23 \pm 18 \%$ $419(0-50 \%)$, and $25 \pm 26 \%(0-75 \%)$, respectively. No participant exceeded clinical thresholds for any of these 420 characteristics. 


\section{$424 \quad 4.0$ Discussion}

425 This study investigated the effect of consuming different commercial beverages (including milk-based 426 beverages with contrasting formulations) with food ad libitum post-exercise on fluid, energy and nutrient recovery 427 in females. Overall, results indicate that, when consumed voluntarily and with food, different beverages are likely to 428 elicit similar levels of fluid recovery. However, caloric beverages, particularly milk-based formulations, appear to 429 increase energy consumption and alter nutrient provision compared to when water is consumed. Findings from this 430 study suggest that, when food is available post-exercise, the type of recovery beverage ingested will influence daily 431 nutrient intake and nutrient intake immediately post-exercise, rather than acute measures of fluid recovery.

Previous research investigating the impact of beverage type on fluid recovery post-exercise generally 434 indicates that milk/milk-based formulations are more effective rehydration agents than water and sports beverages 435 (Shirreffs et al. 2007b; Watson et al. 2008; Desbrow et al. 2014; Seery and Jakeman 2016). However, the majority 436 of studies have "prescribed" fluid intake and denied participants access to food: an approach with limited ecological 437 validity. The current investigation administered beverages and a variety of foods ad libitum in an attempt to simulate 438 real-life post-exercise conditions. Under these circumstances, the different commercial beverages promoted similar 439 levels of fluid recovery (Water: $1352 \pm 462$ g; Sports Drink: $1349 \pm 407$ g; LS-MILK: $1238 \pm 400$ g; HP-MILK: $4401293 \pm 453 \mathrm{~g}$ ); despite differences in the quantity of water consumed and the proportion of water retained between 441 treatments. The only other study employing directly comparable methodology (Campagnolo et al. 2017) 442 demonstrated similar effects in male participants (fluid recovery was not influenced by the choice of water, a sports 443 beverage $\left[\right.$ Powerade $^{\circledR}$ ] or a milk-based formulation [Sustagen Sport ${ }^{\circledR}$ ] when food and fluid were consumed ad 444 libitum). This suggests that post-exercise rehydration is complex and likely to be influenced by the type of beverage 445 provided and the availability of food during recovery. However, additional studies employing protocols that better 446 reflect real-life post-exercise conditions are still required to improve our understanding of the interaction between 447 fluid, food and nutrients in rehydration and recovery after exercise.

448 Previous research suggests that sports drinks, water and milk-based formulations are typically ingested in 449 different quantities when individuals are permitted to consume these beverages ad libitum (Maughan and Leiper 450 1994; Brouns et al. 1998; Park et al. 2012; Baguley et al. 2016; Campagnolo et al. 2017). Indeed, studies 451 consistently report that sports drinks or carbohydrate-electrolyte solutions (CES) increase voluntary fluid 
452 consumption by $\sim 30-42 \%$ compared to water (Maughan and Leiper 1994; Brouns et al. 1998; Park et al. 2012; 453 Campagnolo et al. 2017) and by $>50 \%$ compared to milk-based beverages post-exercise (Baguley et al. 2016; 454 Campagnolo et al. 2017). Each of the different test beverages in the present study were consumed in roughly similar 455 volumes. The inconsistency in findings between the current and previous reports may reflect gender differences. 456 That is, the former studies have predominantly been conducted using male participants and some evidence (albeit in 457 older individuals and/or during exercise) suggests sex differences exist in voluntary fluid consumption for different 458 beverages (Baker et al. 2005). Indeed, Baker et al. (2005) observed that females consumed more water but not CES 459 than males relative to BM. Furthermore, males consumed significantly more CES than water, but intakes between 460 the two beverages for females were not statistically different. Whilst this study examined fluid intake during rest 461 periods interspersed throughout an exercise protocol (and is therefore not directly comparable to the present study), similar behaviors may apply post-exercise.

While beverage intakes were similar on average in this study, it is worthwhile noting that volumes varied 464 considerably at an individual-level (Supplementary Table S2). This may be due to participants having different taste 465 preferences. On examining the data, we can see that participants who indicated Sports Drink was "more pleasant" 466 than Water $(n=2)$ did in fact, consume $\sim 40 \%$ more Sports Drink; whilst those who perceived Sports Drink as "more 467 pleasant" than LS-MILK ( $n=5)$ and HP-MILK $(n=5)$ also consumed $\sim 40 \%$ more of the preferred beverage. The 468 influence of palatability is further demonstrated by the fact that participants consumed a greater amount of their 469 most preferred beverage than their least- and second-least preferred beverages. These data indicate that palatability 470 is an important determinant of fluid intake and that taste preferences can vary greatly amongst individuals. The 471 importance of thirst and beverage palatability as factors influencing fluid intake post-exercise is further supported by 472 results of the current study, where HP-MILK and LS-MILK were consumed in similar volumes. These two 473 beverages had similar sensory characteristics (flavor, mouth-feel, appearance, aroma), yet contrasting nutrient 474 profiles. Clearly, physiological/psychological cues provided when consuming similar tasting beverages with 475 different nutrition are too subtle or participants are unable to detect them to moderate drinking behavior. Thus, 476 individuals likely revert to consuming the beverage to relieve thirst and/or on the basis that they find it 477 palatable/pleasant, which influences intake volume.

478 Findings from this study indicate that food plays an important role in mediating fluid recovery following 479 exercise when beverages with basic nutrient profiles are consumed. Although the present investigation did not 
480 incorporate a "beverage only" trial for direct comparisons, the available evidence suggests that if food is not 481 consumed, just $\sim 30-56 \%$ of water (Maughan and Leiper 1995; Shirreffs and Maughan 1998; Shirreffs et al. 2007a; 482 Shirreffs et al. 2007b; Merson et al. 2008; Wong and Chen 2011; James et al. 2014; Stasiule et al. 2014; Tai et al. 483 2014; Wong et al. 2014; Seery and Jakeman 2016) and 38-64\% of sports drink (Wong et al. 2000; Shirreffs et al. 484 2007a; Shirreffs et al. 2007b; Watson et al. 2008; Evans et al. 2009b; James et al. 2011; Wong and Chen 2011; 485 James et al. 2012; James et al. 2013; Clayton et al. 2014; Desbrow et al. 2014; Tai et al. 2014; Wong et al. 2014; Li 486 et al. 2015; Seery and Jakeman 2016) is typically retained post-ingestion (1.50 L $\left.\mathrm{kg} \mathrm{BM} \operatorname{lost}^{-1}\right)$. Values indicated in 487 the current investigation are noticeably higher (Water: $70.2 \pm 13.6 \%$; Sports Drink: $74.2 \pm 18.1 \%$ ). This observation is 488 consistent with results from previous experiments suggesting that the consumption of food (providing energy and 489 nutrients) enhances fluid retention (Maughan et al. 1996; Pryor et al. 2015) by delaying gastric emptying and 490 attenuating osmotic diuresis (Nose et al. 1988). It is important to note that the male subjects in Campagnolo et al. 491 (2017) retained a very similar proportion of ingested water (Trial \#1: 72 $\pm 8 \%$; Trial \#2: 73 $\pm 11 \%$ ) and Powerade ${ }^{\circledR}$ $492(74 \pm 17 \%)$ as the female participants in the current study, even though females derived roughly half the amount of 493 energy, $\mathrm{CHO}$, protein and sodium (relative to BM) from food across on all beverage treatments. The fact that 494 individuals retained a similar proportion of Water and Sports Drink is also interesting, as it suggests that water may, 495 in fact (contrary to popular belief), be an appropriate rehydration solution when co-ingested with food; particularly, 496 if the calories delivered in sports beverages are not desired. Collectively, these data suggest that consuming food ad 497 libitum after exercise is likely to enhance fluid retention similarly in males and females, despite differences in their 498 dietary behavior.

499 Results from the present study indicate that the choice of recovery beverage can have a profound effect on 500 overall dietary intake. Total energy intake during the $4 \mathrm{~h}$ recovery period increased proportionately to the energy501 density of the experimental beverage (even despite an opposing step-wise reduction in energy consumed from food). 502 An analysis of the participants' post-trial diet records revealed that individuals did not modify their dietary behavior 503 over the remainder of the day to offset this difference in energy consumption. While the caloric beverages increased $504 \mathrm{CHO}$ intake post-exercise (Water: $0.4 \pm 0.2 \mathrm{~g} \mathrm{CHO} \cdot \mathrm{kg}^{-1} \cdot \mathrm{h}^{-1}$; all other treatments: $0.8 \pm 0.2 \mathrm{~g} \cdot \mathrm{kg}^{-1} \cdot \mathrm{h}^{-1}$ ), it is worth noting 505 that ad libitum intake of food and any beverage included in this study failed to meet recommended CHO intakes for 506 "rapid refueling" after exercise; though total daily intakes were within the recommended range $\left(\sim 3.0-5.0 \mathrm{~g} \mathrm{CHO} \cdot \mathrm{kg}^{-}\right.$ $507{ }^{1} \cdot \mathrm{d}^{-1}$ ) (Thomas et al. 2016). Protein consumption during the first $2 \mathrm{~h}$ after exercise was in excess of recommendations 
$508\left(0.25-0.30 \mathrm{~g} \cdot \mathrm{kg}^{-1}\right)$; particularly, when the milk-based beverages were consumed (Water: $0.47 \pm 0.17 \mathrm{~g} \cdot \mathrm{kg}^{-1}$; $\mathrm{Sports}$ 509 Drink: $0.39 \pm 0.09 \mathrm{~g} \cdot \mathrm{kg}^{-1}$; LS-MILK: 0.81 $\pm 0.28 \mathrm{~g} \cdot \mathrm{kg}^{-1}$; HP-MILK: $1.49 \pm 0.41 \mathrm{~g}^{\mathrm{kg}}{ }^{-1}$ ) (Thomas et al. 2016). Total daily 510 protein intakes were generally appropriate (i.e. $\sim 1.2-2.0 \mathrm{~g} \cdot \mathrm{kg}^{-1} \cdot \mathrm{d}^{-1}$ ), but exceeded recommended levels on the HP511 MILK $\left(2.6 \pm 0.8 \mathrm{~g} \cdot \mathrm{kg}^{-1} \cdot \mathrm{d}^{-1}\right)$ (Thomas et al. 2016). Hence, the type of beverage consumed may influence aspects of 512 post-exercise recovery and the suitability of certain beverages for individuals with specific dietary goals). For 513 instance, caloric beverages may facilitate rehydration, substrate repletion and positive energy balance in situations 514 where weight gain or large nutritional intakes are required. Whereas, the consumption of water (with food) should 515 be encouraged to facilitate rehydration without excessive caloric intake in circumstances where weight loss or 516 maintenance is desirable.

This investigation (and results from Campagnolo et al. (2017)) provides evidence that different commercial 519 beverages promote similar levels of fluid recovery after exercise. However, it is important to consider that "rapid 520 rehydration" is typically utilized to facilitate recovery ahead of a subsequent exercise session. Under these 521 circumstances, individuals may restrict their intake of food/fluid to avoid GI discomfort during exercise; potentially 522 affecting fluid and nutrient recovery. Additional research is required to determine the behaviors of athletes given 523 access to ad libitum food and different beverages when they are required to perform a subsequent exercise session; 524 and impact of these behaviors on post-exercise recovery and subsequent exercise performance.

In summary, this study demonstrates that different beverages are similarly effective at replenishing exerciseinduced sweat loss, but result in different energy/nutrient intakes, when consumed ad libitum with food. An athlete's acute nutritional requirements to support recovery, broader dietary goals, taste preferences and access to food should 529 therefore inform selection of the most appropriate recovery beverage.

\subsection{Acknowledgements}

532 This research was funded by the Sanitarium ${ }^{\mathrm{TM}}$ Health and Wellbeing Company and the Australian Institute of 533 Sport. Neither party had a hand in manuscript development, data collection/analysis or the interpretation of findings. 534 
536 This research was funded by the Sanitarium ${ }^{\mathrm{TM}}$ Health and Wellbeing Company and the Australian Institute of Sport.

537 Neither party had a hand in manuscript development, data collection/analysis or the interpretation of findings. The 538 authors have no conflicts of interest to report. 


\section{Reference List}

Armstrong, L.E., Pumerantz, A.C., Fiala, K.A., Roti, M.W., Kavouras, S.A., Casa, D.J., et al. 2010. Human hydration indices: Acute and longitudinal reference values. Int. J. Sport Nutr. Exerc. Metab. 20(2): 145-153. doi:10.1123/ijsnem.20.2.145. PMID:20479488.

Baguley, B.J., Zilujko, J., Leveritt, M.D., Desbrow, B., and Irwin, C. 2016. The effect of ad libitum consumption of a milk-based liquid meal supplement vs. a traditional sports drink on fluid balance after exercise. Int. J. Sport Nutr. Exe. 26(4): 347-355. doi:10.1123/ijsnem.2015-0229. PMID:26693643.

Baker, L.B., Munce, T.A., and Kenney, W.L. 2005. Sex differences in voluntary fluid intake by older adults during exercise. Med. Sci. Sport Exer. 37:S29-S29. doi:10.1097/00005768-200505001-00170. PMID:15870633.

Borg, G. 1998. Borg's perceived exertion and pain scales. Champaign, IL, US: Human Kinetics.

Brouns, F., Kovacs, E.M., and Senden, J.M. 1998. The effect of different rehydration drinks on post-exercise electrolyte excretion in trained athletes. Int. J. Sports Med. 19(1): 56-60. doi:10.1055/s-2007-971881. PMID:9506802.

Campagnolo, N., Iudakhina, E., Irwin, C., Schubert, M., Cox, G.R., Leveritt, M., et al. 2017. Fluid, energy and nutrient recovery via ad libitum intake of different fluids and food. Physiol. Behav. 171: 228-235. doi:10.1016/j.physbeh.2017.01.009. PMID:28104353.

Clayton, D.J., Evans, G.H., and James, L.J. 2014. Effect of drink carbohydrate content on postexercise gastric emptying, rehydration, and the calculation of net fluid balance. Int. J. Sport Nutr. Exerc. Metab. 24(1): 79-89. doi:10.1123/ijsnem.2013-0024. PMID:23980237.

de Lauzon, B., Romon, M., Deschamps, V., Lafay, L., Borys, J.M., Karlsson, J., et al. 2004. The Three-Factor Eating Questionnaire-R18 is able to distinguish among different eating patterns in a general population. J. Nutr. 134(9): 2372-2380. doi:10.1093/jn/134.9.2372. PMID:15333731.

Desbrow, B., Jansen, S., Barrett, A., Leveritt, M.D., and Irwin, C. 2014. Comparing the rehydration potential of different milk-based drinks to a carbohydrate-electrolyte beverage. Appl. Physiol. Nutr. Me. 39(12): 1366-1372. doi:10.1139/apnm-2014-0174. PMID:25315686.

Dye, L. and Blundell, J.E. 1997. Menstrual cycle and appetite control: Implications for weight regulation. Hum. Reprod. 12(6): 1142-1151. doi:10.1093/humrep/12.6.1142. PMID:9221991 
Evans, G.H., Miller, J., Whiteley, S., and James, L.J. 2017. A sodium drink enhances fluid retention during 3 hours of post-exercise recovery when ingested with a standard meal. Int. J. Sport Nutr. Exerc. Metab. 27(4): 344-350. doi:10.1123/ijsnem.2016-0196. PMID:28253022.

Evans, G.H., Shirreffs, S.M., and Maughan, R.J. 2009a. Postexercise rehydration in man: The effects of carbohydrate content and osmolality of drinks ingested ad libitum. Appl. Physiol. Nutr. Me. 34(4): 785-793. doi:10.1139/h09-065. PMID:19767815.

Evans, G.H., Shirreffs, S.M., and Maughan, R.J. 2009b. Postexercise rehydration in man: The effects of osmolality and carbohydrate content of ingested drinks. Nutrition, 25(9): 905-913. doi:10.1016/j.nut.2008.12.014. PMID:19487107.

Frayn, K.N. 1983. Calculation of substrate oxidation rates in vivo from gaseous exchange. J. Appl. Physiol. Respir. Environ. Exerc. Physiol. 55(2): 628-634. doi:10.1152/jappl.1983.55.628. PMID:6618956.

Garner, D.M. 1982. The eating attitudes test: Psychometric features and clinical correlates. Psychol. Med. 12(04): 871. doi:10.1017/S0033291700049163. PMID:6961471.

Garth, A.K. and Burke, L.M. 2013. What do athletes drink during competitive sporting activities? Sports Med. 43(7): 539-564. doi:10.1007/s40279-013-0028-y. PMID:23529286.

James, L.J., Clayton, D., and Evans, G.H. 2011. Effect of milk protein addition to a carbohydrate-electrolyte rehydration solution ingested after exercise in the heat. Br. J. Nutr. 105(3): 393-399. doi:10.1017/s0007114510003545. PMID:20875186.

James, L.J., Evans, G.H., Madin, J., Scott, D., Stepney, M., Harris, R., Stone, R., and Clayton, D.J. 2013. Effect of varying the concentrations of carbohydrate and milk protein in rehydration solutions ingested after exercise in the heat. Br. J. Nutr. 110(7): 1285-1291. doi:10.1017/s0007114513000536. PMID:23721750.

James, L.J., Gingell, R., and Evans, G.H. 2012. Whey protein addition to a carbohydrate-electrolyte rehydration solution ingested after exercise in the heat. J. Athl. Train. 47(1): 61-66. PMID:22488231.

James, L.J., Mattin, L., Aldiss, P., Adebishi, R., and Hobson, R.M. 2014. Effect of whey protein isolate on rehydration after exercise. Amino Acids, 46(5): 1217-1224. doi:10.1007/s00726-014-1680-8. PMID:24500112.

Jeukendrup, A., Brouns, F., Wagenmakers, A.J., and Saris, W.H. 1997. Carbohydrate-electrolyte feedings improve 1 h time trial cycling performance. Int. J. Sports Med. 18(2): 125-9. doi:10.1055/s-2007-972607. PMID:9081269. 
Jones, E.J., Bishop, P.A., Green, J.M., and Richardson, M.T. 2010. Effects of metered versus bolus water consumption on urine production and rehydration. Int. J. Sport Nutr. Exerc. Metab. 20(2): 139-144. doi:10.1123/ijsnem.20.2.139. PMID:20479487.

Leblanc, V., Begin, C., Corneau, L., Dodin, S., and Lemieux, S. 2015. Gender differences in dietary intakes: What is the contribution of motivational variables? J. Hum. Nutr. Diet. 28(1): 37-46. doi:10.1111/jhn.12213. PMID:24527882.

Li, L., Wong, S.H.-S., and Sun, F.-H. 2015. Effects of protein addition to carbohydrate-electrolyte solutions on postexercise rehydration. J. Exerc. Sci. Fit. 13(1): 8-15. doi:10.1016/j.jesf.2014.11.001. PMID:29541093.

Marsh-Richard, D.M., Hatzis, E.S., Mathias, C.W., Venditti, N., and Dougherty, D.M. 2009. Adaptive visual analog scales (AVAS): A modifiable software program for the creation, administration, and scoring of visual analog scales. Behav. Res. Methods, 41(1): 99-106. doi:10.3758/BRM.41.1.99. PMID:19182128.

Maughan, R.J. and Leiper, J.B. 1994. Post exercise rehydration in man: Effects of voluntary intake of four different beverages. Med. Sci. Sports Exerc. 25(S2). PMID:8897383.

Maughan, R.J. and Leiper, J.B. 1995. Sodium intake and post-exercise rehydration in man. Eur. J. Appl. Physiol. Occup. Physiol. 71(4): 311-3199. doi:10.1007/BF00240410. PMID:8549573.

Maughan, R.J., Leiper, J.B., and Shirreffs, S.M. 1996. Restoration of fluid balance after exercise-induced dehydration: Effects of food and fluid intake. Eur. J. Appl. Physiol. Occup. Physiol. 73(3-4): 317-325. doi:10.1007/Bf02425493. PMID:8781863.

McCartney, D., Desbrow, B., and Irwin, C. 2017. The effect of fluid intake following dehydration on subsequent athletic and cognitive performance: A systematic review and meta-analysis. Sports Med. - Open, 3: 13. doi:10.1186/s40798-017-0079-y. PMID:28316054.

McCartney, D., Desbrow, B., and Irwin, C. 2018. Post-exercise ingestion of carbohydrate, protein and water: A systematic review and meta-analysis for effects on subsequent athletic performance. Sports Med. 48(2): 379-408. doi:10.1007/s40279-017-0800-5. PMID:29098657.

Merson, S.J., Maughan, R.J., and Shirreffs, S.M. 2008. Rehydration with drinks differing in sodium concentration and recovery from moderate exercise-induced hypohydration in man. Eur. J. Appl. Physiol. 103(5): 585-594. doi:10.1007/s00421-008-0748-0. PMID:18463891. 
Moore, D.R. 2015. Nutrition to support recovery from endurance exercise: Optimal carbohydrate and protein replacement. Curr. Sports Med. Rep. 14(4): 294-300. doi:10.1249/jsr.0000000000000180. PMID:26166054.

Nose, H., Mack, G.W., Shi, X.R., and Nadel, E.R. 1988. Role of osmolality and plasma-volume during rehydration in humans. J. Appl. Physiol. 65(1): 325-331. doi:10.1152/jappl.1988.65.1.325. PMID:3403476.

O'Neal, E.K., Davis, B.A., Thigpen, L.K., Caufield, C.R., Horton, A.D., and McIntosh, J.R. 2012. Runners greatly underestimate sweat losses before and after a 1-hr summer run. Int. J. Sport Nutr. Exe. 22(5): 353-362. PMID:23011653.

Park, S.G., Bae, Y.J., Lee, Y.S., and Kim, B.J. 2012. Effects of rehydration fluid temperature and composition on body weight retention upon voluntary drinking following exercise-induced dehydration. Nutr. Res. Prac. 6(2): 126-131. doi:10.4162/nrp.2012.6.2.126. PMID:22586501.

Poppitt, S.D. 1996. Short-term effects of alcohol consumption on appetite and energy intake. Physiol. Behav. 60(4): 1063-1070. doi:10.1016/0031-9384(96)00159-X. PMID:8884934.

Pryor, J.L., Johnson, E.C., Del Favero, J., Monteleone, A., Armstrong, L.E., and Rodriguez, N.R. 2015. Hydration status and sodium balance of endurance runners consuming post exercise supplements of varying nutrient content. Int. J. Sport Nutr. Exerc. Metab. 25(5): 471-479. doi:10.1123/ijsnem.2014-0231. PMID:25811075.

Ray, M.L., Bryan, M.W., Ruden, T.M., Baier, S.M., Sharp, R.L., and King, D.S. 1998. Effect of sodium in a rehydration beverage when consumed as a fluid or meal. J. Appl. Physiol. 85(4): 1329-1336. doi:10.1152/jappl.1998.85.4.1329. PMID:9760324.

Sawka, M.N., Burke, L.M., Eichner, E.R., Maughan, R.J., Montain, S.J., and Stachenfeld, N.S. 2007. American college of sports medicine position stand: Exercise and fluid replacement. Med. Sci. Sports Exerc. 39(2): 377390. doi:10.1249/mss.0b013e31802ca597. PMID:17277604.

Seery, S. and Jakeman, P. 2016. A metered intake of milk following exercise and thermal dehydration restores whole-body net fluid balance better than a carbohydrate-electrolyte solution or water in healthy young men. Br. J. Nutr. 116(6): 1013-1021. doi:10.1017/s0007114516002907. PMID:27477047.

Shirreffs, S.M., Aragon-Vargas, L.F., Keil, M., Love, T.D., and Phillips, S. 2007a. Rehydration after exercise in the heat: A comparison of 4 commonly used drinks. Int. J. Sport Nutr. Exe. 17(3): 244-258. PMID:17693686. 
Shirreffs, S.M. and Maughan, R.J. 1998. Volume repletion after exercise-induced volume depletion in humans: Replacement of water and sodium losses. Am. J. Physiol. 274(5 Pt 2): F868-875. doi:10.1152/ajprenal.1998.274.5.F868. PMID:9612323.

Shirreffs, S.M., Watson, P., and Maughan, R.J. 2007b. Milk as an effective post-exercise rehydration drink. Br. J. Nutr. 98(1): 173-180. doi:10.1017/s0007114507695543. PMID:17459189.

Stasiule, L., Capkauskiene, S., Vizbaraite, D., and Stasiulis, A. 2014. Deep mineral water accelerates recovery after dehydrating aerobic exercise: A randomized, double-blind, placebo-controlled crossover study. J. Int. Soc. Sport Nutr. 11(1): 34. doi:10.1186/1550-2783-11-34. PMID:25002835.

Tai, C.-Y., Joy, J.M., Falcone, P.H., Carson, L.R., Mosman, M.M., Straight, J.L., et al. 2014. An amino acidelectrolyte beverage may increase cellular rehydration relative to carbohydrate-electrolyte and flavored water beverages. Nutr. J. 13(1): 47. doi:10.1186/1475-2891-13-47. PMID:24884613.

Thomas, D.T., Erdman, K.A., and Burke, L.M. 2016. Position of the Academy of Nutrition and Dietetics, dietitians of canada, and the American College of Sports Medicine: Nutrition and athletic performance. J. Acad. Nutr. Diet. 116(3): 501-528. doi:10.1016/j.jand.2015.12.006. PMID:26920240.

Watson, P., Love, T.D., Maughan, R.J., and Shirreffs, S.M. 2008. A comparison of the effects of milk and a carbohydrate-electrolyte drink on the restoration of fluid balance and exercise capacity in a hot, humid environment. Eur. J. Appl. Physiol.. 104(4): 633-642. doi:10.1007/s00421-008-0809-4. PMID:18618137.

Wemple, R.D., Morocco, T.S., and Mack, G.W. 1997. Influence of sodium replacement on fluid ingestion following exercise-induced dehydration. Int. J. Sport Nutr. 7(2): 104-116. doi:10.1007/s00421-008-0809-4. PMID:9189781.

Wong, S.H.-S. and Chen, Y. 2011. Effect of a carbohydrate-electrolyte beverage, lemon tea, or water on rehydration during short-term recovery from exercise. Int. J. Sport Nutr. Ex. 21(4): 300-310. doi:10.1249/01.MSS.0000401356.49966.c6. PMID:21813913.

Wong, S.H., Williams, C., and Adams, N. 2000. Effects of ingesting a large volume of carbohydrate-electrolyte solution on rehydration during recovery and subsequent exercise capacity. Int. J. Sport Nutr. Exe. 10(4): 375393. doi:10.1123/ijsnem.10.4.375. PMID:1 1099366. 
Wong, S.H.S., Sun, F.H., Huang, W.Y.J., and Chen, Y.J. 2014. Effects of beverages with variable nutrients on rehydration and cognitive function. Int. J. Sports Med. 35(14): 1208-1215. doi:10.1055/s-0034-1370968. PMID:25203651.

Zderic, T.W., Coggan, A.R., and Ruby, B.C. 2001. Glucose kinetics and substrate oxidation during exercise in the follicular and luteal phases. J. Appl. Physiol. 90(2): 447-453. doi:10.1152/jappl.2001.90.2.447. PMID:11160041. 


\section{Tables}

Table 1. Pre-trial conditions and exercise-induced dehydration

\begin{tabular}{lcccccc}
\hline & Water & Sports Drink & LS-MILK & HP-MILK & F-ratio & $p$-value \\
\hline Pre-exercise U & & & & & \\
SG & $1.012 \pm 0.005$ & $1.014 \pm 0.007$ & $1.013 \pm 0.005$ & $1.014 \pm 0.008$ & $\mathrm{~F}(3,21)=0.547$ & 0.656 \\
Pre-exercise PSM $_{\left.\mathrm{OSOsm} \cdot \mathrm{kg}^{-1}\right)}$ & $286 \pm 5$ & $286 \pm 8$ & $287 \pm 4$ & $287 \pm 3$ & $\mathrm{~F}(1.4,8.4)=0.172$ & 0.770 \\
Pre-exercise BM (kg) & $61.98 \pm 10.78$ & $61.68 \pm 10.86$ & $61.28 \pm 10.53$ & $61.56 \pm 10.80$ & $\mathrm{~F}(3,21)=1.69$ & 0.201 \\
BM loss (kg) & $1.20 \pm 0.19$ & $1.21 \pm 0.15$ & $1.22 \pm 0.16$ & $1.23 \pm 0.10$ & $\mathrm{~F}(3,21)=0.151$ & 0.928 \\
BM loss (\%) & $1.96 \pm 0.28$ & $2.00 \pm 0.43$ & $2.03 \pm 0.31$ & $2.03 \pm 0.26$ & $\mathrm{~F}(3,21)=0.388$ & 0.763 \\
Total eEE (kJ) & $3241 \pm 349$ & $3289 \pm 388$ & $3270 \pm 457$ & $3164 \pm 264$ & $\mathrm{~F}(3,21)=0.805$ & 0.505 \\
\hline
\end{tabular}

BM: Body mass; eEE: Estimated energy expenditure; HP-MILK: Up \& Go Energize ${ }^{\mathrm{TM}}$; $\mathrm{P}_{\mathrm{OSM}}$ : Plasma osmolality; LS-MILK: $\mathrm{Up} \&$ Go Reduced Sugar ${ }^{\mathrm{TM}} ; \mathrm{U}_{\mathrm{SG}}$ : Urine specific gravity. Plasma osmolality values from $n=7$ participants where blood sampling was performed. Values are Mean \pm SD. 
Table 2. Total nutrient intake from food and beverages during the $4 \mathrm{~h}$ recovery period and entire trial day (trial plus posttrial diet).

\begin{tabular}{|c|c|c|c|c|c|c|c|}
\hline & Water & Sports Drink & LS-MILK & HP-MILK & F-ratio & $p$-value & $\eta_{\mathrm{p}}^{2}$ \\
\hline \multicolumn{8}{|c|}{ Nutrient Intake From Beverage } \\
\hline Beverage Intake (g) & $1790 \pm 540$ & $1801 \pm 359$ & $1538 \pm 485$ & $1639 \pm 587$ & $\mathrm{~F}(3,21)=1.32$ & 0.294 & 0.16 \\
\hline Water $(g)$ & $1790 \pm 540^{c}$ & $1711 \pm 339^{b}$ & $1299 \pm 410$ & $1383 \pm 495$ & $\mathrm{~F}(3,21)=5.72$ & 0.005 & 0.45 \\
\hline Energy $(\mathrm{kJ})$ & $0 \pm 0^{a, b, c}$ & $1874 \pm 371^{b, c}$ & $4282 \pm 1337$ & $5639 \pm 2019$ & $\mathrm{~F}(1.3,9.3)=48.8$ & $<0.001$ & 0.88 \\
\hline $\mathrm{CHO}(\mathrm{g})$ & $0 \pm 0^{a, b, c}$ & $104 \pm 21$ & $136 \pm 42$ & $162 \pm 58$ & $\mathrm{~F}(3,21)=45.8$ & $<0.001$ & 0.87 \\
\hline Protein $(g)$ & $0 \pm 0^{b, c}$ & $0 \pm 0^{b, c}$ & $52 \pm 16^{c}$ & $110 \pm 39$ & $\mathrm{~F}(3,21)=59.6$ & $<0.001$ & 0.90 \\
\hline Fat $(\mathrm{g})$ & $0 \pm 0^{b, c}$ & $0 \pm 0^{b, c}$ & $23 \pm 7$ & $25 \pm 9$ & $\mathrm{~F}(3,21)=63.2$ & $<0.001$ & 0.90 \\
\hline Sodium (mg) & $0 \pm 0^{a, b, c}$ & $504 \pm 101^{b, c}$ & $1000 \pm 315^{c}$ & $1639 \pm 587$ & $\mathrm{~F}(1.2,8.7)=48.3$ & $<0.001$ & 0.87 \\
\hline Beverage Mass (kg) & $1.79 \pm 0.54$ & $1.80 \pm 0.36$ & $1.54 \pm 0.48$ & $1.64 \pm 0.59$ & $\mathrm{~F}(3,21)=1.32$ & 0.294 & 0.16 \\
\hline \multicolumn{8}{|c|}{ Nutrient Intake From Food } \\
\hline Water (g) & $128 \pm 59$ & $98 \pm 57$ & $160 \pm 75$ & $140 \pm 78$ & $\mathrm{~F}(3,21)=1.66$ & 0.206 & 0.19 \\
\hline Energy (kJ) & $4129 \pm 1080^{b, c}$ & $3292 \pm 633^{c}$ & $1737 \pm 1171$ & $1457 \pm 797$ & $\mathrm{~F}(3,21)=17.4$ & $<0.001$ & 0.71 \\
\hline $\mathrm{CHO}(\mathrm{g})$ & $107 \pm 34^{b, c}$ & $75 \pm 18^{c}$ & $52 \pm 25$ & $42 \pm 19$ & $\mathrm{~F}(3,21)=17.0$ & $<0.001$ & 0.71 \\
\hline Protein $(g)$ & $29 \pm 9^{c}$ & $24 \pm 8$ & $10 \pm 10$ & $8 \pm 7$ & $\mathrm{~F}(3,21)=12.4$ & $<0.001$ & 0.64 \\
\hline Fat $(\mathrm{g})$ & $47 \pm 14^{c}$ & $42 \pm 13^{c}$ & $17 \pm 21$ & $15 \pm 15$ & $\mathrm{~F}(3,21)=11.8$ & $<0.001$ & 0.63 \\
\hline Sodium (mg) & $735 \pm 334^{b, c}$ & $738 \pm 345^{c}$ & $208 \pm 241$ & $205 \pm 208$ & $F(1.4,9.7)=12.9$ & 0.003 & 0.65 \\
\hline Food Mass (kg) & $0.32 \pm 0.86^{c}$ & $0.25 \pm 0.74$ & $0.25 \pm 0.11$ & $0.21 \pm 0.88$ & $\mathrm{~F}(3,21)=4.13$ & 0.019 & 0.37 \\
\hline \multicolumn{8}{|c|}{ Total Nutrient Intake (Food \& Beverage) } \\
\hline Water $(g)$ & $1918 \pm 580$ & $1809 \pm 338$ & $1458 \pm 431$ & $1523 \pm 472$ & $\mathrm{~F}(3,21)=4.92$ & 0.010 & 0.41 \\
\hline Energy (kJ) & $4129 \pm 1080$ & $5167 \pm 643$ & $6019 \pm 1925$ & $7096 \pm 2058$ & $\mathrm{~F}(1.5,10.4)=7.37$ & 0.014 & 0.51 \\
\hline $\mathrm{CHO}(\mathrm{g})$ & $107 \pm 34^{a, b, c}$ & $180 \pm 30$ & $188 \pm 46$ & $204 \pm 47$ & $\mathrm{~F}(3,12)=12.9$ & $<0.001$ & 0.65 \\
\hline Protein $(g)$ & $29 \pm 9^{b, c}$ & $24 \pm 8^{b, c}$ & $63 \pm 20^{c}$ & $118 \pm 41$ & $\mathrm{~F}(1.3,9.1)=33.8$ & $<0.001$ & 0.83 \\
\hline Fat $(g)$ & $47 \pm 14$ & $42 \pm 13$ & $40 \pm 24$ & $40 \pm 19$ & $F(1.4,9.8)=0.437$ & 0.590 & 0.06 \\
\hline Sodium (mg) & $735 \pm 334^{a, c}$ & $1242 \pm 322$ & $1208 \pm 298^{c}$ & $1844 \pm 488$ & $\mathrm{~F}(1.5,10.5)=10.7$ & 0.005 & 0.61 \\
\hline Total Mass (kg) & $2.11 \pm 0.57$ & $2.05 \pm 0.35$ & $1.79 \pm 0.52$ & $1.85 \pm 0.55$ & $\mathrm{~F}(3,21)=2.27$ & 0.110 & 0.25 \\
\hline \multicolumn{8}{|c|}{ Nutrient Intake For Entire Trial Day } \\
\hline Water (L) & $4.0 \pm 1.4$ & $4.0 \pm 1.1$ & $3.9 \pm 1.0$ & $3.7 \pm 1.4$ & $F(3,21)=0.65$ & 0.592 & 0.09 \\
\hline Energy (MJ) & $8.4 \pm 2.4$ & $9.9 \pm 2.2$ & $11.0 \pm 3.1$ & $10.8 \pm 2.5$ & $\mathrm{~F}(3,21)=3.71$ & 0.028 & 0.35 \\
\hline $\mathrm{CHO}(\mathrm{g})$ & $201 \pm 77^{b}$ & $285 \pm 65$ & $323 \pm 85$ & $295 \pm 69$ & $\mathrm{~F}(3,21)=6.83$ & 0.002 & 0.49 \\
\hline Protein $(g)$ & $89 \pm 33^{c}$ & $93 \pm 35^{c}$ & $110 \pm 30^{c}$ & $156 \pm 41$ & $\mathrm{~F}(3,21)=10.8$ & $<0.001$ & 0.61 \\
\hline Fat $(\mathrm{g})$ & $86 \pm 23$ & $84 \pm 29$ & $88 \pm 34$ & $73 \pm 26$ & $F(3,21)=0.98$ & 0.365 & 0.12 \\
\hline Sodium $(\mathrm{g})$ & $2.1 \pm 0.3$ & $2.5 \pm 0.2$ & $3.3 \pm 0.5$ & $3.1 \pm 0.3$ & $F(3,21)=4.68$ & 0.012 & 0.40 \\
\hline
\end{tabular}

CHO: Carbohydrate; HP-MILK: Up \& Go Energize ${ }^{\mathrm{TM}}$; LS-MILK: Up \& Go Reduced Sugar ${ }^{\mathrm{TM}}$. Values are Mean \pm SD. $a$, mean value significantly different from Sports Drink; $b$, mean value significantly different from LS-MILK; $c$, mean value significantly different from HP-MILK. 


\section{Figure Captions}

Figure 1. Schematic representation of the experimental procedures. BM: nude body mass; CRT: choice reaction time cognitive task (for experimental blinding); Food: ad libitum access to snack foods for $15 \mathrm{~min}$; Met: metabolic gas measurements; $\mathrm{P}_{\mathrm{OSM}}$ : blood collection for plasma osmolality analyses; SFQ: Subjective Feelings Questionnaire; $\mathrm{U}_{\mathrm{SG}}$ : urine specific gravity.

Figure 2. Hourly urine output (A) and $\mathrm{U}_{\mathrm{SG}}$ values (B) under each of the experimental treatments. Values are

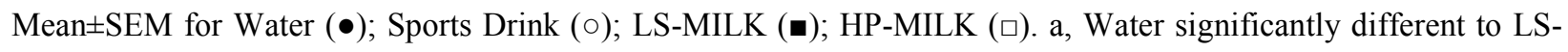
MILK and HP-MILK; b, Sports Drink significantly different to LS-MILK and HP-MILK; c, Sports Drink trending for a significant difference from LS-MILK and HP-MILK ( $<<0.100)$. H1-4: Hours 1 to 4 of the recovery period.

Figure 3. Net BM responses under each of the experimental treatments. Values are Mean \pm SEM for Water $(\bullet)$; Sports Drink (०); LS-MILK (๘); HP-MILK (口). H1-4: Hours 1 to 4 of the recovery period. 
$\begin{array}{rllllll}07: 00 & 08: 30 & 09: 30 & 10: 30 & 11: 30 & 12: 30 & 1: 30\end{array}$

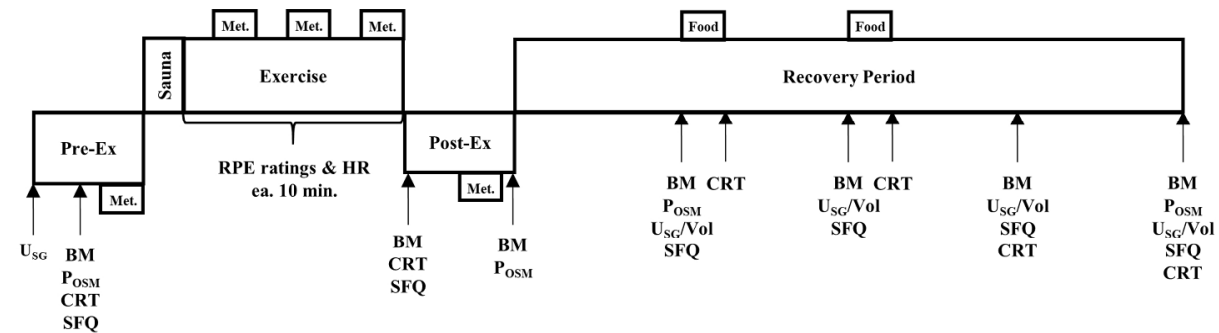

Figure 1. Schematic representation of the experimental procedures. BM: nude body mass; CRT: choice reaction time cognitive task (for experimental blinding); Food: ad libitum access to snack foods for 15 min; Met: metabolic gas measurements; Posm: blood collection for plasma osmolality analyses; SFQ: Subjective Feelings Questionnaire; $U_{S G}$ : urine specific gravity.

$194 \times 70 \mathrm{~mm}(300 \times 300 \mathrm{DPI})$ 

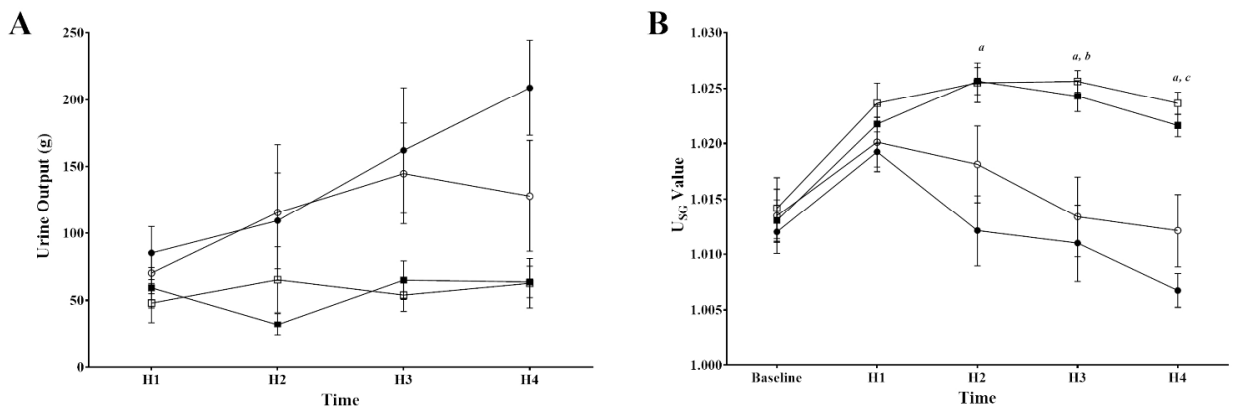

Figure 2. Hourly urine output $(A)$ and $U_{S G}$ values $(B)$ under each of the experimental treatments. Values are Mean \pm SEM for Water $(\bullet)$; Sports Drink (o); LS-MILK (घ); HP-MILK ( $\square)$. a, Water significantly different to LSMILK and HP-MILK; $b$, Sports Drink significantly different to LS-MILK and HP-MILK; $c$, Sports Drink trending for a significant difference from LS-MILK and HP-MILK $(p<0.100)$. H1-4: Hours 1 to 4 of the recovery period.

$219 \times 77 \mathrm{~mm}(300 \times 300$ DPI $)$ 


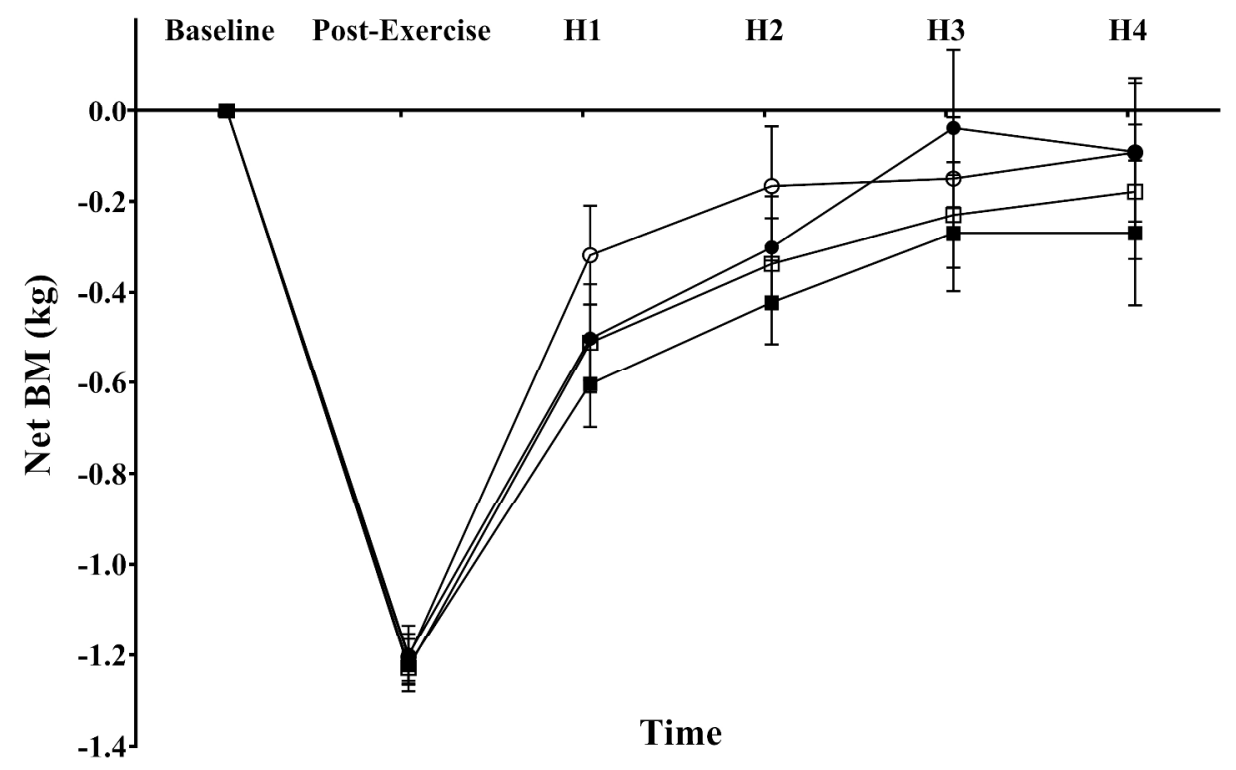

Figure 3. Net BM responses under each of the experimental treatments. Values are Mean \pm SEM for Water $(\bullet)$; Sports Drink (०); LS-MILK (•); HP-MILK ( $\square)$. H1-4: Hours 1 to 4 of the recovery period.

$281 \times 172 \mathrm{~mm}(300 \times 300 \mathrm{DPI})$ 